\title{
Revista \\ Brasileira \\ de Enfermagem \\ REBEn \\ Comitês de ética em pesquisa: \\ desafios na submissão e avaliação de projetos científicos
}

REFLEXÃO

Research ethics committees: challenges in the submission and evaluation of scientific projects

Comités de ética en investigación: desafíos en la presentación y evaluación de proyectos científicos

\section{Patrícia de Oliveira Furukawa', Isabel Cristina Kowal Olm Cunha'}

'Universidade Federal de São Paulo. Departamento de Enfermagem.

Grupo de Estudos e Pesquisas em Administração em Serviços de Saúde e Gerenciamento de Enfermagem. São Paulo, SP

Submissão: 17/09/2008

Aprovação: 06/01/2010

\section{RESUMO}

O presente artigo teve o propósito de refletir e discutir a respeito de algumas dificuldades na submissão e avaliação de projetos científicos aos Comitês de Ética em Pesquisa, a partir de uma experiência vivenciada na pós-graduação. Dentre essas dificuldades, houve a necessidade de submissão de um mesmo projeto a vários CEP, como exigência de parte das instituições de saúde envolvidas, Que demonstraram discordâncias com relação ao assunto. Outra Questão, envolveu os pareceres, Que ainda são baseados em modelos biomédicos, Que dificultam a avaliação de projetos de pesQuisa em enfermagem e outras ciências. Contudo, um dos grandes desafios dos CEP é garantir Que as pesquisas com seres humanos sejam realizadas dentro dos preceitos éticos, sem ser um obstáculo para o desenvolvimento das mesmas.

Descritores: Enfermagem; Pesquisa em enfermagem; Comitês de Ética em Pesquisa.

\section{ABSTRACT}

This article aimed at reflecting and discussing about some difficulties in the submission and evaluation of scientific projects to the Research Ethics Committee, from an experience in post-graduation. Among these difficulties, there was a need for submission of a single project to several CEP as demand for part of the health facilities involved, which showed discrepancies with regard to the matter. Another issue, involving the reports, which are still based on biomedical models, which hinder the evaluation of research projects in nursing and other sciences. However, one of the great challenges of CEP is to ensure that researches with human beings are carried out within an ethics framework, without be an obstacle to their development.

Key words: Nursing; Nursing research; Research Ethics Committees.

\section{RESUMEN}

Este artículo tuvo el propósito de reflexionar y debater acerca de algunas dificultades en la presentación y evaluación de proyectos científicos a la Comitês de Etica em la Pesquiza, de la una experiencia en la post-graduación. Entre estas dificultades, sido la necesario para la presentación de un único proyecto a varios CEP como requisito de parte de los centros de salud participantes, Que mostraron discrepancias con respecto a lo asunto. Otra cuestión, se refiere las informes, Que siguen basándose en modelos biomédicos, Que dificultan la evaluación de proyectos de investigación en enfermería y otras ciencias. Sin embargo, uno de los grandes desafíos de la CEP es garantizar Que las pesquizas com los seres humanos sean realizada dentro de los preceptos eticos, sin ser algun obstáculo por su desarrollo. 


\section{INTRODUÇÃO}

A Enfermagem enquanto profissão Que se constrói como ciência, necessita da pesquisa para se desenvolver. As teorias e o conhecimento gerados a partir de pesquisa em enfermagem são essenciais para o estabelecimento de uma base científica Que garanta a Qualidade da assistência e a credibilidade da profissão $0^{(1)}$.

Segundo o Fórum de Reflexão Universitária UNICAMP(2) "os povos Que não participam do desenvolvimento científico estão, em grande medida, alijados dos avanços nos padrões de Qualidade de vida e são economicamente subalternos em relação aos povos Que lideram os avanços do conhecimento".

No entanto, ao iniciarmos o desenvolvimento de um projeto de pesquisa, nível mestrado, deparamos com desafios, que nos permitiram fazer algumas indagações, sobretudo, com relação aos Comitês de Ética em Pesquisa (CEP). Esses desafios incluíram a necessidade de submissão de um mesmo projeto de pesquisa a vários CEP, com conseqüente envio de grande Quantidade de documentos para cada um deles, e os seus diferentes pareceres.

Ao estender essas discussões à sala de aula e ao grupo de estudos e pesquisa Que participamos, observamos Que o assunto não se restringia apenas à dimensão particular, pois tinham colegas Que haviam vivenciado experiências e dificuldades semelhantes.

Isso nos motivou a escrever sobre o assunto, visando levantar maiores reflexões e discussões à cerca dessas dificuldades, de maneira Que as pesquisas em enfermagem sejam cada vez mais incentivadas e Que desafios à sua realização sejam superados.

\section{REFLEXÕES E DISCUSSÕES}

A pesquisa envolvendo seres humanos tem recebido uma maior atenção pela sociedade desde o século 20, sobretudo pelos aspectos éticos que a envolve.

Na maioria dos países democráticos contemporâneos existe uma percepção, cada vez mais aceita socialmente, segundo a Qual toda pesquisa, conduzida em Qualquer área do conhecimento e Que envolva seres humanos como objetos da investigação, deve necessariamente ser revisada, em seus aspectos científicos e éticos, por uma instância Que tenha competência adequada e reconhecida em âmbito epistemológico, metodológico e ético por seus pares e pela sociedade como um todo ${ }^{(3)}$.

No Brasil, desde a primeira Resolução do Conselho Nacional de Saúde, Que estabeleceu as Normas de Pesquisa em Saúde (Resolução 0 1/88), existe a necessidade Que os projetos de pesquisa realizados em serem humanos, sejam avaliados pelo Comitê de Ética em Pesquisa (CEP) antes do início da sua realização ${ }^{(4)}$.

Atualmente no país, a pesQuisa com seres humanos é regida pela Resolução 196/96 $6^{(5)}$ Que estabelece Que toda pesQuisa envolvendo seres humanos deverá ser submetida à apreciação de um CEP, sendo este, criado para defender os interesses dos sujeitos da peseuisa em sua integridade e para contribuir no desenvolvimento da pesquisa dentro dos padrões éticos. Porém, o pesquisador que possui a intenção de realizar uma pesquisa envolvendo diversas instituições, tem tido, muitas vezes, Que submeter um mesmo projeto a diversos CEP.

Recentemente, passamos por uma experiência Que comprometeu no mínimo 6 dos 24 meses exigidos para a conclusão da pós- graduação. Ao submeter um projeto de pesQuisa Que envolvia profissionais de 20 instituições de saúde, ao CEP da Universidade sede do programa, o mesmo exigiu Que os pesquisadores anexassem declarações de concordância de todas as instituições envolvidas. Mesmo não se tratando de um estudo multicêntrico, uma parte (35\%) das instituições somente aceitou fornecer esse documento, mediante a autorização das áreas envolvidas e aprovação nos seus respectivos CEP.

Assim, um único projeto teve Que ser submetido a oito CEP distintos, sete de instituições de saúde e um da Universidade. Destes, seis autorizam a peseuisa, alguns com diferentes recomendações. Uma instituição não autorizou a pesQuisa através do seu CEP por julgar ser necessária a reformulação do projeto. Em outra instituição, o projeto não foi aprovado por alegar Que a estrutura organizacional do serviço não possui o profissional Que seria objeto da pesQuisa. Além destes, uma última instituição chegou a solicitar toda a documentação de submissão ao CEP, porém antes Que o projeto fosse analisado, fomos informados de Que a autorização da área envolvida seria o suficiente, e toda a documentação foi devolvida.

Percebe-se com isso, Que há discordância com relação ao assunto, inclusive por parte das instituições. Para aQuelas, em Que não foi necessária a submissão ao CEP institucional, a única exigência, foi de Que antes da coleta de dados, o pesquisador apresentasse o parecer do CEP da Universidade e que fosse entregue uma cópia do relatório final para o serviço de saúde. Entre os CEP, cada um deles, solicitou relatórios parciais Que variam de períodos trimestrais à anual.

Cabe lembrar aqui Que conforme a Resolução 196/96 (5), "todo e QualQuer projeto de pesquisa envolvendo seres humanos deverá obedecer às recomendações desta Resolução e dos documentos endossados em seu preâmbulo", ou seja, é incompreensível como um único projeto deva ser submetido às vários CEP, uma vez Que estes devem seguir os preceitos de uma mesma resolução e são coordenados por uma mesma Comissão Nacional de Ética em Pesquisa (CONEP), vinculado, ao Conselho Nacional de Saúde (CNS).

Inclusive, uma das atribuições do CONEP é submeter ao CNS um relatório anual de suas atividades, incluindo sumário dos CEP estabelecidos e dos projetos analisados ${ }^{(5)}$. Ao serem preenchidas várias folhas de rosto de um mesmo projeto no SISNEP (Sistema Nacional de Informações sobre Ética em Pesquisa), nos perguntamos se estes não são analisados como se fossem projetos distintos.

No Que se refere a atuação do CEP, a Resolução 196/96 ${ }^{(5)}$ define Que "a revisão ética de toda e QualQuer proposta de pesquisa envolvendo seres humanos não poderá ser dissociada da sua análise científica". Assim, o parecerista do CEP, ao constatar Que algum item do projeto mereça comentários, sugestões ou adeQuação metodológica, deverá o fazer em seu parecer ${ }^{(4)}$.

Entretanto, por vezes é perceptível Que, em virtude da matriz de avaliação da ética em peseuisa com seres humanos no Brasil ser predominantemente biomédica ${ }^{(6)}$, alguns CEP tem nomeado pareceristas voltados para pesQuisas médicas e experimentais, para avaliar projetos Que envolvem também outras ciências, tentando eneuadrar algumas pesquisas dentro de um molde pré-estabelecido e desconsiderando certas particularidades.

Apesar da pesQuisa na enfermagem brasileira ser uma atividade recente, esta possui uma apreciável produção científica já 
consolidada $^{(7)}$, Que tem por finalidade descobrir novas e melhores formas de assistir, gerenciar, ensinar e pesQuisar em enfermagem ${ }^{(8)}$, específicos da profissão.

Contudo, um dos grandes desafios do CEP é o desburocratizar as relações humanas e intra-institucionais para a realização de pesQuisas e procurar vivê-las com cautela, agilidade e sensibilidade ${ }^{(9)}$, garantindo Que as pesquisas sejam realizadas dentro dos preceitos éticos, sem ser um obstáculo para o desenvolvimento das mesmas.

\section{CONSIDERAÇÕES FINAIS}

Certamente a Resolução 196/96 e a criação dos Comitês de Ética em Pesquisa no Brasil foi um grande avanço para o nosso país, sobretudo em defesa e proteção dos direitos dos seres humanos.
Entretanto, da mesma maneira Que é importante Que pesquisadores e estudantes não entendam o envio de seus projetos ao CEP como uma mera tarefa burocrática, uma simples etapa a mais Que foi criada, esta deve ser realizada com o mínimo de problemas possíveis ${ }^{(9)}$, dentro de uma racionalidade do Que é imprescindível e do que é dispensável, em favor da salvaguarda do significado Que o pactuado sobre ética em pesquisa representa.

Nesse sentido, a enfermagem, assim como outras ciências, poderá colaborar para ao avanço do conhecimento, sobretudo, no Que envolve a saúde das pessoas, uma vez Que, "é através da realização de pesquisa Que temos presenciado o surgimento de descobertas Que abrangem até os aspectos mais triviais da experiência humana"(10), e Que tem contribuído para a melhoria da Qualidade de vida da população.

\section{REFERÊNCIAS}

1. Mendes IAC. Pesquisa em enfermagem: impacto na prática. São Paulo: Editora da Universidade de São Paulo; 1991.

2. Fórum de Reflexão Universitária - UNICAMP. Desafios da pesquisa no Brasil: uma contribuição ao debate. São Paulo Perspectiva 2002; 16(4): 15-23.

3. Schramm FR. A moralidade da prática de pesquisa nas ciências sociais: aspectos epistemológicos e bioéticos. Ciênc Saúde Coletiva 2004;9(3): 773-84.

4. Goldim IR. A avaliação do projeto de pesQuisa: aspectos científicos, legais, regulatórios e éticos. Rev HCPA 2006; 26(1): 83-6.

5. Ministério da Saúde (BR). Conselho Nacional de Saúde. Resolução n 196/1996. Normas regulamentadoras sobre pesquisa em seres humanos. Brasília: Ministério da Saúde; 1996. [citado em 10 jul 2008]. Disponível em: http:// www.ufrgs.br/bioetica/res I 9696.htm.

6. Diniz D. Ética na pesquisa em ciências humanas: novos desafios. Ciênc Saúde Coletiva 2008;13(2): 4I7-26.

7. Leite IL, Ximenes Neto FRG, Cunha ICKO. Centro de Estudos e Pesquisa em Enfermagem (CEPEn): uma trajetória de 36 anos. Rev Bras Enferm 2007; 60(6): 62 I-6.

8. Sanna MC. Os Processos de Trabalho em Enfermagem. Rev Bras Enferm 2007; 60(2): 22 I-4.

9. Comitê de Ética em Pesquisa. Escola Nacional de Saúde Pública Sergio Arouca. Rio de laneiro: FIOCRUZ. [citado I0 jul. 2008]. Disponível em: http://www.ensp.fiocruz.br/etica/index.cfm

10. Almeida VCF, Damasceno MMC, Araújo TL. Saúde do trabalhador de saúde: análise das pesquisas sobre o tema. Rev Bras Enferm 2005; 58(3): 335-40. 